
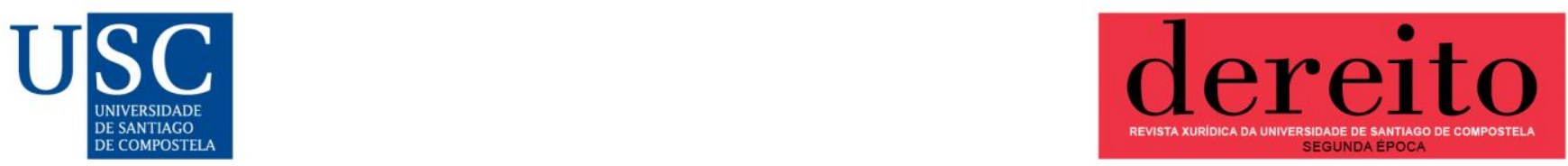

Dereito: revista xurídica da Universidade de Santiago de Compostela, 30 (1), 2021. ISSN: 2174-0690

https://doi.org/10.15304/dereito.30.1.7533

Estudios

\title{
Administración concursal y cuestiones laborales de la insolvencia a raíz del Real Decreto Legislativo 1/2020, de 5 de mayo, por el que se aprueba el texto refundido de la Ley Concursal
}

\author{
Bankruptcy Administration and labour issues in insolvency following Royal \\ Legislative Decree $1 / 2020$ of 5 may approving the consolidated text of the \\ Bankruptcy Law
}

\section{César Gilo Gómez}

Abogado. Doctor en Derecho. Universidad de Salamanca.

cesargilo@usal.es

\section{Resumen}

Inherente a los concursos de acreedores son las situaciones laborales que el propio funcionamiento de la actividad empresarial del concursado suscita. En este sentido, la correcta gestión del capital humano del deudor se convierte en una cuestión esencial de todo procedimiento concursal, tanto si se alcanza un convenio como si la solución es liquidativa, responsabilidad que recae en gran medida en el órgano de la Administración Concursal a partir de su nombramiento a raíz de la declaración de insolvencia del deudor, órgano que se verá obligado a adoptar importantes decisiones en un escenario inestable por definición.

El Real Decreto Legislativo 1/2020, de 5 de mayo, por el que se aprueba el texto refundido de la Ley Concursal ratifica la importancia del órgano concursal en la aportación de soluciones a las situaciones laborales que se producen en el seno de todo procedimiento concursal.

Palabras clave: Administración Concursal, funciones, laboral, unidad productiva, Ley Concursal

\begin{abstract}
Inherent in insolvency proceedings are the employment situations that the operation of the insolvency proceedings itself gives rise to. In this sense, the proper management of the human capital of the debtor becomes an essential issue in any bankruptcy proceedings, whether an agreement is reached or the solution is liquidation, liability largely borne by the insolvency body upon its appointment following the debtor's insolvency, which will be obliged to take important decisions in an unstable scenario by definition.

Royal Legislative Decree 1/2020 of 5 May, approving the revised text of the Bankruptcy Law, confirms the importance of the bankruptcy body in providing solutions to the labour situations that occur in any bankruptcy proceedings.
\end{abstract}

Keywords: Bankruptcy administration, duties, labour, unit of production, bankruptcy law 


\section{INTRODUCCIÓN}

Una de las cuestiones más importantes que suscita todo procedimiento concursal son las situaciones laborales que plantea la insolvencia del deudor. Y es que la incapacidad para hacer frente a las obligaciones regularmente exigibles conlleva que los primeros afectados sean los propios trabajadores a cargo del deudor.

El marco normativo del derecho laboral español viene dado por el Real Decreto-ley 3/2012, de 10 de febrero, de medidas urgentes para la reforma del mercado laboral, reforma que se sitúa en pleno debate político por la posibilidad de que el actual ejecutivo decida derogarla o finalmente solo modificarla. Todo ello provoca que las importantes decisiones que debe tomar la Administración Concursal-entre otras, decisiones extintivas de contratos laborales- deban efectuarse bajo un marco regulatorio provisional que debería aclararse lo antes posible, ya que es necesario que la normativa laboral se encuentre perfectamente coordinada con la normativa concursal.

Mientras ello se decide, el papel de la Administración Concursal en este sentido y como no podría ser de otra forma, sigue siendo fundamental en un aspecto tan importante para la viabilidad de la actividad económica del deudor, como es la regulación de la relación entre el deudor concursado y el capital humano del que éste dispone.

La entrada en vigor desde el pasado 1 de septiembre de 2020 del Real Decreto Legislativo $1 / 2020$, de 5 de mayo, por el que se aprueba el texto refundido de la Ley Concursal refrenda las funciones de la Administración Concursal, conservando su papel principal como eje vertebrador de la estructura laboral del deudor.

Éstas y otras cuestiones relacionadas con la actuación de la Administración Concursal en materia laboral son objeto de cuanto se expone a continuación.

\section{FUNCIONES ENCOMENDADAS A LA ADMINISTRACIÓN CONCURSAL EN MATERIA LABORAL}

El artículo 33.c de la Ley 22/2003, de 9 de julio, Concursal —en adelante LC-era el encargado de atribuir a la Administración Concursal cinco funciones en materia laboral, funciones en unos casos más genéricas y en otras más específicas.

Con la aprobación el pasado 1 de septiembre de 2020 del Real Decreto Legislativo 1/2020, de 5 de mayo, por el que se aprueba el texto refundido de la Ley Concursal —en adelante TRLC - ha desaparecido de la regulación normativa un precepto que aglutinara la totalidad de las funciones encomendadas a la Administración Concursal ${ }^{1}$.

Referidas funciones han sido ahora trasladadas a lo largo de la totalidad del nuevo texto normativo. De esta forma, la referencia particular a las cinco funciones laborales que se le 
encomendaba a la Administración Concursal en el apartado "c" del artículo 33 de la extinta Ley, aparecen en el nuevo TRLC distribuidas en diferentes preceptos a partir del 169.

\section{LA INTERVENCIÓN DE LA ADMINISTRACIÓN CONCURSAL EN LOS PROCEDIMIENTOS DE MODIFICACIÓN SUSTANCIAL DE LAS CONDICIONES DE TRABAJO}

\subsection{La relevancia del informe de la Administración Concursal en los procedimientos de modificación sustancial de las Condiciones de Trabajo}

Como continuación a lo expuesto, entre las funciones encomendadas a la Administración Concursal se encuentra la de iniciar procedimientos de modificación sustancial de las condiciones de trabajo y la de intervenir en referidos procedimientos. Ello venía siendo objeto de regulación en el artículo 64 LC, que era el precepto que establecía las reglas para proceder a la tramitación de los mismos, el cual tiene su oportuna correspondencia en los actuales artículos 169 y siguientes TRLC.

Nos encontramos ante una materia cuyo contenido ha sido objeto de numerosas reformas en la anterior normativa vigente hasta septiembre de 2020, prueba de que es un precepto con importantes consecuencias jurídicas para la viabilidad económica del deudor, sobre cuyos efectos se ha actuado continuamente.

En este sentido, se comienza atribuyendo a la Administración Concursal la función de dar cumplimiento a las resoluciones judiciales que hubieran recaído a la fecha de declaración de concurso en materia laboral, es decir, las decisiones que se produzcan en relación a modificaciones sustanciales de condiciones de trabajo, traslados, despidos, suspensión de contratos y reducción de jornada. Nos encontramos ante un mandato que el legislador refundidor ha querido incluir expresamente pero que se corresponde básicamente con el deber genérico de acatar las resoluciones judiciales.

Llamamos la atención en primer lugar respecto a la cláusula de cierre del artículo 169 TRLC, la cual insiste en señalar que en todo aquello no previsto en la subsección $1^{\text {a }}$ relativa a los efectos sobre los contratos de trabajo, se aplicará la legislación laboral. Y es que no puede perderse de vista la vigencia de las normas del procedimiento laboral en el concurso, extremo que el legislador se ha encargado de dejar claro en diversos apartados del texto normativo concursal ${ }^{2}$.

Con carácter general, la importancia de la actuación de la Administración Concursal en esta materia viene dada de base por ser su informe de las masas del concurso elaborado a tenor del artículo 293 TRLC, el que va a tomarse de referencia para evaluar la viabilidad de las operaciones de modificación de las condiciones laborales que se pretenden acometer. 
Y es que no debe olvidarse que el informe que debe confeccionar la Administración Concursal en el plazo de dos meses desde que se produzca la aceptación del cargo constituye un completo análisis de la masa activa y de la masa pasiva del deudor que permitirá justificar ante el Juez del concurso la variación de las condiciones laborales propuestas ${ }^{3}$.

Así, el informe servirá al Juez del concurso para ilustrarse completamente respecto al activo con el que cuenta la concursada, el número de trabajadores que la integran, su categoría y salarios. Igualmente, el mismo le servirá para tener detalle de los acreedores y de las obligaciones a las que tiene que hacer frente la empresa y que provocan la necesidad de adoptar una medida colectiva de carácter laboral. Además de todo ello, contará con un juicio técnico y experto que le ayudará a valorar la decisión que deba tomarse, a tenor del contenido de los análisis y exposiciones recogidas en el artículo 292 TRLC.

No obstante lo expuesto, debe destacarse que el artículo 172 TRLC prevé expresamente la posibilidad de que se adopten las medidas colectivas sin necesidad de esperar al informe de la Administración Concursal siempre que se estime que la demora en la aplicación de las mismas pueda afectar gravemente la viabilidad futura de la empresa y el empleo o causar grave perjuicio a los trabajadores. El legislador establece esta salvaguarda ante la posibilidad de que se produzcan una serie de perjuicios consecuencia del retraso provocado en espera a que la Administración Concursal confeccione el informe.

En relación a ello, llamamos la atención respecto al verbo utilizado por el legislador: "estimar"4. Desde aquí entendemos que para justificar la adopción de las medidas colectivas en un momento tan primigenio, no es suficiente con que se "estime" que se van a producir unos perjuicios. Al contrario, para adelantar una decisión como ésta sin disponer del informe técnico de la Administración Concursal, deberá contarse con otro tipo de documentación que acredite suficientemente la necesidad de adoptar las mismas con urgencia o que al menos den al Juzgador una base argumental para entender cautelarmente la viabilidad de estas medidas ${ }^{5}$. No obstante lo expuesto, entendemos que, a pesar de la anticipación provisional de las medidas, las mismas deberán venir o no definitivamente refrendadas por el informe de la Administración Concursal, ya que será el momento en el que, tras el estudio técnico de la situación económica y patrimonial del deudor, se conocerá con certeza si las medidas adoptadas fueron o no correctas.

\subsection{La intervención de la Administración Concursal en la tramitación del procedimiento de modificación de Condiciones Laborales}

Además de por la elaboración del informe, la Administración Concursal es igualmente una parte fundamental en la tramitación del procedimiento de modificación de condiciones laborales que prevén los artículos 169 TRLC y siguientes. Y es que como en la propia subsección se recoge, ésta podrá solicitar al Juez el inicio de referido procedimiento, participará en las consultas, negociará un acuerdo, podrá suscribirlo, será oída por la autoridad laboral y podrá interponer recurso de suplicación contra el Auto que lo acuerde. Además de todo ello, si a la fecha de declaración del concurso, ya existiera referida modificación de condiciones laborales, será la Administración Concursal la encargada de ejecutar tales medidas. 
Debe recordarse que no nos encontramos ante ningún mandato judicial, sino que lo que hace el legislador en este aspecto es recordar que la Administración Concursal está legitimada activamente para que, en caso de estimarlo procedente, poder iniciar determinados procedimientos laborales en aras de garantizar la continuidad de la actividad económica del deudor. Es ésta una función prevista para aquellas situaciones en las que las facultades del deudor sean suspendidas, sustituyendo al mismo la Administración Concursal.

Además, si bien el legislador encomienda expresamente a la Administración Concursal la facultad de iniciar procedimientos laborales relacionados con los contratos de trabajo vigentes a la fecha de declaración de concurso, también le atribuye la posibilidad de intervenir en referidos procedimientos cuando no sea ésta quien los haya iniciado. Con ello el legislador claramente pretende prever todos los supuestos que pueden darse, facultando aquí a la Administración Concursal para intervenir en los procedimientos iniciados por el deudor concursado, supuesto en el que evidentemente las facultades de éste no se encuentran suspendidas, sino meramente intervenidas y donde la actuación de la Administración Concursal es mucho menos intensa que en aquellos procedimientos iniciados a instancia de ésta.

\section{ADMINISTRACIÓN CONCURSAL Y CONTRATOS DE ALTA DIRECCIÓN}

La importancia cuantitativa que tiene para el procedimiento concursal los contratos del personal de alta dirección que pudiera tener suscritos el deudor es evidente, dadas las retribuciones normalmente elevadas del personal que integra esta categoría dentro de una persona jurídica.

Pero igualmente debe tenerse en cuenta la importancia cualitativa que estos profesionales han tenido y pueden seguir teniendo para la persona jurídica que se encuentra en concurso. Y es que es necesario destacar que nos encontramos ante profesionales que ejercitan poderes inherentes a la titularidad jurídica de la empresa y que en multitud de ocasiones son quienes han llevado a la misma a la situación de insolvencia en la que se encuentra. Ello conlleva que sean consecuentemente los que mejor conocen el funcionamiento de ésta y sus problemas, por lo que la relación de la Administración Concursal con el personal de alta dirección deberá ser por un lado colaborativa, dado el grado de información del que este personal dispone respecto al funcionamiento de la sociedad, y por el otro fiscalizadora de su actuación pasada y presente, ya que en función de ésta la Administración Concursal deberá decidir si solicita o no un cambio en el régimen de toma de decisiones en la sociedad, pasando de la intervención a la suspensión de facultades (108.1 TRLC).

En este sentido, el artículo 186 TRLC no se encarga de regular la relación entre la Administración Concursal y el personal de alta dirección (la cual, salvando las distancias, puede ser muy similar a la que se pudiera tener con el deudor) sino que este precepto lo que hace es otorgar a la Administración Concursal diferentes posibilidades de actuación respecto a los contratos suscritos con estos trabajadores de la sociedad6.

Otro de los aspectos más relevantes en este sentido es el contenido en el artículo 188 TRLC relativo a la posibilidad que se otorga a la Administración Concursal de solicitar al Juez del 
concurso un aplazamiento en el pago del crédito que pudiera haber surgido del derecho a la indemnización suscitada a raíz de la extinción del contrato de trabajo de los altos directivos. Referida solicitud de aplazamiento obedece a dos factores: de un lado a la cuantía normalmente importante de referido crédito, cuyo pago inmediato podría poner en entredicho los intentos de viabilidad de la actividad económica del deudor, y por el otro - y es aquí donde más ha insistido la doctrina- en la posible complicidad que pudieran tener los altos directivos de la empresa en la situación actual de insolvencia por la que atraviesa la misma7.

Con todo ello, el legislador ha querido, dada la especialidad del personal laboral que se encuadra en el grupo de "alta dirección", prever la posibilidad que igualmente tiene la Administración Concursal de actuar sobre los contratos del personal que integra este grupo y que en ocasiones, su correcta adaptación a la situación de la empresa se convierte en fundamental, dado el volumen habitualmente elevado de la retribución de referidos profesionales.

Estrechamente relacionada con la función anterior y en consecuencia con ésta se encuentra la última de las labores encomendadas expresamente por el legislador a la Administración Concursal en materia laboral y a la que hacíamos referencia anteriormente. Y es que en caso de actuar sobre los contratos del personal de alta dirección, particularmente en caso de tener que extinguir los mismos, la importante retribución pactada con estos profesionales podría ocasionar que su pago inmediato provocase la inviabilidad económica transitoria de una solución convenida que permitiese el mantenimiento de la actividad del deudor. Es por esta razón que el legislador ha querido dotar a la Administración Concursal de la posibilidad de solicitar el aplazamiento en el pago de las indemnizaciones correspondientes al personal de alta dirección, para que ello no sea un obstáculo de cara a tomar determinadas decisiones respecto a este tipo de contratos cuya extinción puede ser la solución para asegurar la viabilidad de la empresa concursada8.

Una de las principales novedades a las que se tiene que enfrentar el órgano de la Administración Concursal será la figura del Director General. Este concepto no aparecía en la anterior normativa pero sin embargo en ésta adquiere una especial relevancia por cuanto se hace referencia a este cargo de responsabilidad en hasta once preceptos del nuevo TRLC, siendo evidente su vinculación con el personal de alta dirección y su posición en representación del deudor concursado en los casos de concursos de personas jurídicas. En esencia, lo que se produce es una sustitución de la figura de los apoderados generales ${ }^{9}$ por la de directores generales, adaptándolo a la terminología actual, concretando y acotando el concepto, ya que el ánimo del legislador es referirse a aquellas personas con poder de dirección sin necesidad de ostentar condición de administración alguna. Aunque ambos términos no son sinónimos, prueba de la sustitución de conceptos buscada por el legislador- refundidor la encontramos en la redacción del artículo 442 TRLC relativo al concurso culpable en el que se ha sustituido "apoderados generales" por "directores generales" en cuanto a la intervención que estas figuras pudieran haber tenido en la generación o agravación del estado de insolvencia 10 . 


\section{EL PAPEL DE LA ADMINISTRACIÓN CONCURSAL EN LA VENTA DE LA UNIDAD PRODUCTIVA}

Los efectos laborales de la venta de la unidad productiva han experimentado una importante modificación en la actual normativa del TRLC vigente desde el 1 de septiembre de 2020. El nuevo régimen establecido, dados los probados beneficios que la venta de la unidad productiva produce, ha buscado potenciar las mismas introduciendo una nueva regulación que bordea el límite competencial de un Texto Refundido.

Así, por primera vez se prevé la definición de unidad productiva en el artículo 200.2 TRLC, precepto que establece el mandato legal a la Administración Concursal para que identifique y describa referida unidad productiva como anejo del inventario.

Lo relevante se encuentra en que la regulación de la venta de las unidades productivas ha dejado de incluirse en la fase de liquidación, conteniéndose ahora en sede del inventario de la masa activa que la Administración Concursal debe confeccionar. De esta forma, la Administración Concursal deberá dedicar parte de su trabajo en la confección del inventario de la masa activa para describir aquellos establecimientos, explotaciones y unidades productivas que integran el patrimonio del deudor. Referida descripción se efectuará, según el mandato legal contenido en el artículo 200.1 TRLC, como un anejo del inventario.

A la hora de enajenar la unidad productiva, se produce una importante precisión en el nuevo TRLC que afecta directamente al estatuto de la Administración Concursal, más concretamente a su retribución. Y es que si en el anterior texto normativo se establecía que la transmisión de la unidad productiva, en aquellos casos en los que se produjera mediante enajenación directa, se realizaría a través de entidad especializada con cargo a la retribución de la Administración Concursal (artículo 149.1.1 LC) el refundidor ha añadido una precisión en el artículo 216.3 TRLC por el que se indica que la retribución de la entidad especializada se realizará con cargo a la retribución que la Administración Concursal haya percibido. De esta forma, si bien con la anterior normativa podía entenderse que el pago de la entidad especializada podría esperar al efectivo cobro por parte de la Administración Concursal, el actual TRLC pone el foco respecto a la retribución ya percibida, por lo que el pago de los honorarios de la entidad especializada deberá efectuarse de inmediato tan pronto la Administración Concursal haya percibido la cantidad suficiente como para abonar sus honorarios y con cargo a éstos, no pudiendo demorar el pago ${ }^{11}$. Sin embargo, sigue suscitándose la duda en aquellos supuestos en los que la Administración Concursal no haya cobrado remuneración alguna.

Es de destacar el deber impuesto a la Administración Concursal conforme al artículo 217 TRLC de especificar con carácter previo a la iniciación del plazo para presentar las ofertas, los gastos en los que ha incurrido la masa para la conservación de la unidad productiva que se pretende enajenar así como presupuestar los gastos futuros hasta la adjudicación definitiva12.

Así mismo, debe destacarse la importancia de la nueva previsión contenida en el artículo 224.1.3 TRLC, al circunscribir en la sucesión de empresa los créditos laborales y de la seguridad social correspondientes a los trabajadores que integren la unidad productiva transmitida ${ }^{13}$. 
No obstante lo expuesto, debe valorarse que no se haya introducido a día de hoy en nuestro ordenamiento la posibilidad de que, en aquellos supuestos de solicitud de concurso con presentación de plan de liquidación para la adquisición de unidad productiva en funcionamiento (artículo 530 LC) pudiera conocerse la identidad de la Administración Concursal antes de comenzarse el proceso. Se echa en falta en este sentido, para dar aún más celeridad a este procedimiento, que la solicitud de concurso con transmisión de unidad productiva viniese de alguna forma avalada o con el visto bueno de la futura Administración Concursal para dar una mayor rapidez y seguridad a esta fase crítica donde los tiempos son elementales.

\section{ADMINISTRACIÓN CONCURSAL Y FONDO DE GARANTÍA SALARIAL}

La participación del Fondo de Garantía Salarial -FOGASA - en el concurso de acreedores continúa siendo muy importante. El artículo 514 TRLC es el nuevo precepto base que establece la intervención subsidiaria del fondo. Sin embargo y a pesar de la refundición del TRLC, la regulación del FOGASA en los procedimientos concursales sigue viniendo regulada en el artículo 33 del Real Decreto Legislativo 2/2015, de 23 de octubre, por el que se aprueba el texto refundido de la Ley del Estatuto de los Trabajadores ${ }^{14}$.

Dadas las escasas novedades en la regulación del FOGASA —-más allá de la ubicación sistemática de los preceptos - y el consecuente hecho de que el legislador refundidor no haya incorporado las soluciones jurisprudenciales dadas a situaciones controvertidas, produce que se sigan suscitando los mismos problemas que ya provocaba la figura ${ }^{15}$.

Su relación con la Administración Concursal sigue siendo directa en lo relativo al abono de las cantidades reconocidas por el órgano concursal, siendo parte en los procesos declarativos que se tramiten así como en el incidente concursal en materia laboral ${ }^{16}$. Por ello, el informe de la Administración Concursal elaborado conforme al artículo 293 TRLC, es fundamental para el órgano estatal, ya que es el que determina la existencia, cuantía y calificación del crédito que ostenta. Por ello, su vinculación al informe (específicamente a la lista de acreedores) es esencial y su reacción al mismo haciendo uso de los medios impugnatorios establecidos legalmente es fundamental si no quiere verse sometida a las consecuencias de su no impugnación en plazo ${ }^{17}$.

\section{CONCLUSIONES}

El escenario en el que se sitúa el Derecho concursal tras la aprobación del TRLC y la declaración de estado de alarma a consecuencia de la pandemia provocada por el virus COVID-19 es radicalmente distinto al que nos encontrábamos hace tan solo un año.

En una situación de desconcierto como en la que actualmente estamos inmersos, la materia laboral asociada a todo concurso de acreedores va a erigirse en fundamental una vez se judicialicen las situaciones de insolvencia suscitadas por las consecuencias económicas provocada por la paralización de la actividad a la que la pandemia ha obligado. 
Cuestiones como la venta de las unidades productivas en globo van a resultar fundamentales para la viabilidad del deudor concursado, momento en el que el papel de la Administración Concursal se va a erigir en fundamental para culminar con éxito una operación donde la rapidez y la interlocución con el resto de actores del proceso (posible adquiriente, deudor, Juez del concurso y acreedores) van a ser esenciales.

Por todo ello, los profesionales integrantes del órgano de la Administración Concursal deben estar especialmente preparados para las operaciones que van a tener que afrontarse a partir del mes de marzo de 2021 en el que finalizará la suspensión del plazo para solicitar la declaración de concurso conforme a lo establecido en el Real Decreto-ley 34/2020, de 17 de noviembre, de medidas urgentes de apoyo a la solvencia empresarial y al sector energético, y en materia tributaria.

\section{Bibliografía}

ASENSIO PASCUAL, C. (2020). Aspectos de contenido innovador de la venta de la unidad productiva a la luz del nuevo TRLC. Diario La Ley, no 9660, Sección Tribuna, Wolters Kluwer

BARROS GARCÍA, M. (2020). Algunas cuestiones laborales destacables del nuevo texto refundido de la Ley concursal. Trabajo y Derecho, no 70, Sección Práctica Jurídica y Despachos Profesionales / Estudios de práctica jurídica, Wolters Kluwer

CANO MARCO, F. (2020). El nuevo Texto Refundido de la Ley Concursal y los aspectos laborales del concurso. Diario La Ley, no 9726, Sección Doctrina, Wolters Kluwer.

CASANELLAS BASSOLS, R. (2006). La actuación de la administración concursal ante el personal de alta dirección. Revista de Derecho Concursal y Paraconcursal, no 4, Sección Varia, Primer semestre de 2006, pp. 269.

COHEN BENCHETRIT, A. (2020). La venta de la unidad productiva en el nuevo escenario concursal. Revista de Derecho Concursal y Paraconcursal, no 33, Sección Ponencias, Wolters Kluwer, pp. 79-90.

GILO GÓMEZ, C. (2020). La Administración Concursal en el Real Decreto Legislativo 1/2020, de 5 de mayo, por el que se aprueba el Texto Refundido de La Ley Concursal. LA LEY Mercantil no 72, Editorial Wolters

HERNÁNDEZ SAINZ, E. (2020). La restricción de la sanción de inhabilitación a las personas naturales en el Texto Refundido de la Ley Concursal y sus perniciosos efectos en supuestos de concurso culpable de sociedades administradas por una persona jurídica. LA LEY mercantil, no 73, Sección Empresa y empresario / Doctrina, Wolters Kluwer

HERRERA CUEVAS, E.J. (2005). Aproximación al nuevo Derecho Concursal del Trabajo. Revista de Derecho Concursal y Paraconcursal, no 2/2005, Sección Estudios, p. 97

LATORRE CHINER, N. (2013). El apoderado general en la Ley Concursal. Revista de Derecho Concursal y Paraconcursal, no 19, Sección Estudios, Editorial Wolters Kluwer, pp. 65-80

MONTOYA MELGAR, A. (2012). Contrato de trabajo y concurso de acreedores. Revista de Derecho Concursal y Paraconcursal, no 16, Sección Estudios, p. 25.

THERY MARTÍ, A. (2020). Una segunda oportunidad para las unidades productivas. Revista de Derecho Concursal y Paraconcursal, no 33, Sección Estudios, Wolters Kluwer, p. 249-264

URIZ ÁLVAREZ, J.J. (2012). La actuación del fondo de garantía salarial ante el procedimiento concursal. El concurso laboral, edición no 1, Editorial LA LEY, Madrid. 
${ }^{1}$ Eliminación que expresamente aplaudimos al entender que la situación anterior provocaba una importante inseguridad jurídica al pretenderse detallar sin éxito en un precepto la totalidad de las innumerables funciones que lleva a cabo la Administración Concursal con el evidente riesgo de indeterminación que ello suponía. Nos remitimos en este sentido a la crítica que efectuábamos en GILO GÓMEZ, C. (2020). La Administración Concursal en el Real Decreto Legislativo 1/2020, de 5 de mayo, por el que se aprueba el Texto Refundido de La Ley Concursal. LA LEY Mercantil ${ }^{\circ}$ 72, Wolters Kluwer.

${ }^{2}$ Como cláusula de seguridad, dado lo sensible de la materia laboral y de sus precedentes judiciales, se articula el recurso de suplicación contra las resoluciones del Juez del concurso en este aspecto para que termine siendo la Sala de lo Social del Tribunal Superior de Justicia de la Comunidad Autónoma a la que pertenezca la provincia donde se sitúa el Juzgado de lo Mercantil que está conociendo del procedimiento concursal, la que finalmente resuelva sobre estos aspectos. Vid. en relación a ello Sentencia Tribunal Superior de Justicia de Cataluña (Sala de lo Social) de 27 de septiembre de 2005 (Sentencia 7204/2005) en la que se deja claro, tras el oportuno recurso de suplicación formulado contra el Auto del Juez del concurso que acuerda la extinción colectiva de los contratos de trabajo, que el Juez de lo Mercantil no solo puede autorizar referida extinción colectiva, sino también decretarla.

3 Vid. en este sentido HERRERA CUEVAS, E.J. (2005). Aproximación al nuevo Derecho Concursal del Trabajo. Revista de Derecho Concursal y Paraconcursal, $n^{\circ}$ 2/2005, Sección Estudios, p. 97, quien ha venido entendiendo como lógica esta tempestividad dado que será en ese momento cuando el Juez del concurso contará con una información fiable de la situación financiera y patrimonial de la empresa deudora, elaborada por un órgano no parcial y experto, al que harán referencia las solicitudes, y lo que permitirá valorar una solicitud de modificación, suspensión o extinción colectiva.

${ }^{4}$ Según el diccionario de la RAE, el verbo "estimar" en su cuarta acepción lo define como: Creer o considerar algo a partir de los datos que se tienen.

${ }^{5}$ Existen precedentes judiciales respecto a esta excepción, anteriormente regulada en el artículo 64.3 LC. En este sentido, destacamos el pronunciamiento contenido en el Auto del Juzgado de lo Mercantil n ${ }^{\circ} 1$ de Cádiz de fecha 22 de mayo de 2007 (Expediente de Extinción Colectiva de Relaciones de trabajo n $^{\circ} 151 / 2007$ ) en el que el Juzgado se pronuncia acerca de si cabe la anticipación de las medidas por razones distintas de la viabilidad prevista legalmente, señalándose en la resolución judicial que en el supuesto objeto de enjuiciamiento la anticipación al informe de la Administración Concursal se explica no en conseguir la viabilidad futura de la empresa, sino entre otros factores, en evitar que los trabajadores estén varios meses sin cobrar.

${ }^{6}$ Tal y como pone de relieve el profesor y Magistrado MONTOYA MELGAR, a diferencia de lo que ocurre con los ERE concursales, en los que la decisión del procedimiento corresponde a la autoridad judicial, en estos casos de medidas extintivas o suspensivas individuales es la Administración Concursal la habilitada para decidir por sí dichas medidas. Vid. en este aspecto MONTOYA MELGAR, A. (2021). Contrato de trabajo y concurso de acreedores. Revista de Derecho Concursal y Paraconcursal, n 16, Sección Estudios, p. 25.

7 Vid. en este sentido CASANELLAS BASSOLS, R. (2006). La actuación de la administración concursal ante el personal de alta dirección. Revista de Derecho Concursal y Paraconcursal, n 4, Sección Varia, p. 269.

${ }^{8}$ No obstante, echa en falta el Magistrado CANO MARCO que no se haya aprovechado el TRLC para aclarar si las solicitudes de la Administración Concursal para moderar o aplazar la indemnización del alto directivo se tramitan o no a través del incidente concursal en materia laboral. Vid. CANO MARCO, F. (2020). El nuevo Texto Refundido de la Ley Concursal y los aspectos laborales del concurso. Diario La Ley, $\mathrm{n}^{\circ}$ 9726, Sección Doctrina, Wolters Kluwer.

9 Vid. respecto a la regulación de los apoderados generales en el texto normativo concursal vigente hasta el 1 de septiembre de 2020 LATORRE CHINER, N. (2013). El apoderado general en la Ley Concursal. Revista de Derecho Concursal y Paraconcursal, $n^{\circ}$ 19, Sección Estudios, Wolters Kluwer, pp. 65-80.

${ }^{10}$ Destaca HERNÁNDEZ SAINZ, E. (2020). La restricción de la sanción de inhabilitación a las personas naturales en el Texto Refundido de la Ley Concursal y sus perniciosos efectos en supuestos de concurso culpable de sociedades administradas por una persona jurídica, en LA LEY mercantil, $n^{\circ} 73$, Sección Empresa y empresario / Doctrina, Wolters Kluwer como los administradores o liquidadores pueden ser personas jurídicas, sin que existan restricciones a la forma que pueden adoptar y como en la práctica, el administrador persona jurídica suele tener la forma de sociedad limitada o anónima, no impidiendo que cualquier otro ente dotado de personalidad jurídica ocupe el cargo 
${ }^{11}$ Vid. ASENSIO PASCUAL, C. (2020). Aspectos de contenido innovador de la venta de la unidad productiva a la luz del nuevo TRLC. Diario La Ley, $n^{\circ}$ 9660, Sección Tribuna, Wolters Kluwer, quien se pregunta si impediría la redacción literal del precepto solicitar que dichos honorarios de la entidad especializada fueran a cargo de la masa y no a cargo de los honorarios de la Administración Concursal.

${ }^{12}$ Llama la atención la imputación subjetiva que se realiza en el propio enunciado del precepto: Determinaciones a cargo de la administración concursal, haciéndose en el mismo referencia a la necesidad de determinar una serie de cuestiones como el plazo o los gastos, especificaciones que correrán a cargo de la propia Administración Concursal.

${ }^{13}$ La competencia para declarar la existencia de sucesión de empresa es una cuestión que ha venido suscitando cierta polémica en nuestros tribunales, llegando incluso a pronunciarse el Tribunal Supremo. No obstante todo ello, el TRLC zanja la cuestión y atribuye directamente la competencia para declarar la sucesión de empresa al Juez del concurso en su artículo 211. Vid. respecto a ello BARROS GARCÍA, M. (2020). Algunas cuestiones laborales destacables del nuevo texto refundido de la Ley concursal. Trabajo y Derecho, $n^{\circ} 70$, Sección Práctica Jurídica y Despachos Profesionales / Estudios de práctica jurídica, Wolters Kluwer, quien destaca cómo el nuevo TRLC da un giro copernicano en esta materia, superándose la dualidad de órdenes jurisdiccionales anterior.

${ }^{14}$ Lo que obliga a los operadores jurídicos a acudir a referido texto normativo paralelamente.

${ }^{15}$ En este sentido, coincidimos con la magistrada COHEN BENCHETRIT respecto a la conveniencia de adoptar medidas que incrementen el papel del FOGASA en lo relativo al salario de los trabajadores hasta el traspaso de la unidad productiva. Vid. COHEN BENCHETRIT, A. (2020). La venta de la unidad productiva en el nuevo escenario concursal. Revista de Derecho Concursal y Paraconcursal, n 33, Sección Ponencias, Wolters Kluwer, pp. 79-90.

${ }^{16} \mathrm{El}$ artículo $541.1 \mathrm{TRLC}$ ha ampliado el ámbito objetivo del incidente concursal en materia laboral en comparación con lo previsto en el antiguo artículo 64.8 LC. Vid. respecto a ello THERY MARTÍ, A. (2020). Una segunda oportunidad para las unidades productivas. Revista de Derecho Concursal y Paraconcursal, n 33, Sección Estudios, Wolters Kluwer, pp. 249264, donde se destaca la relevancia de la ampliación de este ámbito.

17 Vid. en este sentido URIZ ÁLVAREZ, J.J. (2012). La actuación del fondo de garantía salarial ante el procedimiento concursal. El concurso laboral, edición n $n^{\circ}$, Editorial LA LEY, Madrid, quien añade que consecuentemente, negar la legitimación al FOGASA para recurrir o impugnar los informes supondría dejarlo en una absoluta indefensión. 